\title{
Decline in cerebral glucose utilisation and cognitive function with aging in Down's syndrome
}

\author{
MARK B SCHAPIRO,* JAMES V HAXBY,* CHERYL L GRADY,* \\ RANJAN DUARA, * NICHOLAS L SCHLAGETER,* BEVERLY WHITE, $\dagger$ \\ ANGELA MOORE,* MAGESH SUNDARAM,$*$ STEVEN M LARSON, \\ STANLEY I RAPOPORT*
}

From the Laboratory of Neurosciences, Section on Brain Aging and Dementia,* National Institute on Aging, Laboratory of Cell Biology and Genetics, $\dagger$ National Institute of Arthritis, Diabetes, and Digestive and Kidney Diseases, Department of Nuclear Medicine, $¥$ Clinical Center, National Institutes of Health, Bethesda, MD, USA

SUMMARY The cerebral metabolic rate for glucose (CMRglc) was measured with positron emission tomography and [18F]2-fluoro-2-deoxy-D-glucose in 14 healthy subjects with Down's syndrome, 19 to 33 years old, and in six healthy Down's syndrome subjects over 35 years, two of whom were demented. Dementia was diagnosed from a history of mental deterioration, disorientation and hallucinations. All Down's syndrome subjects were trisomy 21 karyotype. CMRglc also was examined in 15 healthy men aged 20-35 years and in 20 healthy men aged 45-64 years. All subjects were at rest with eyes covered and ears plugged. Mean hemispheric CMRglc in the older Down's syndrome subjects was significantly less, by $23 \%$, than in the young Down's syndrome group; statistically significant decreases in regional metabolism (rCMRglc) also were present in all lobar regions. $\stackrel{\odot}{\circ}$ Comparison of the younger control group with the older control group showed no difference in CMRglc or any rCMRglc ( $p>0.05$ ). Assessment of language, visuospatial ability, attention and memory showed significant reductions in test scores of the old as compared with the young Down's? syndrome subjects. These results show that significant age differences in CMRglc and rCMRglao occur in Down's syndrome but not in healthy controls, and that, although only some older Down's: syndrome subjects are demented, significant age reductions in neuropsychologic variables occur in all of them.

Down's syndrome is a genetic disorder in which an extra portion of chromosome 21 leads to short stature, minor phenotypic abnormalities, mental retardation, and later precocious aging and dementia. ${ }^{1}$ The pathological basis of the mental retardation is uncertain. Brains of young adult Down's syndrome individuals show no consistent abnormalities aside from subnormal weight, ${ }^{2}$ smallness of the frontal lobes, operculum, superior temporal gyrus and cerebellum, ${ }^{1}$ and calcification of the basal ganglia. ${ }^{3}$ Microscopic studies demonstrate loss of granular neurons in the cerebral cortex ${ }^{4}$ and heterotopias in the cerebellar and cerebral cortices. ${ }^{1}$

Address for reprint requests: Mark B Schapiro, MD, Laboratory of Neurosciences, National Institute on Aging, National Institutes of Health, Bldg 10, Rm 12S235, Bethesda, MD 20892, USA.

Received 14 February 1986 and in revised form 13 August 1986. Accepted 13 September 1986
With more satisfactory treatment of cardiac and infectious disease, more individuals with Down's syndrome are surviving to older ages. Since 1876, when Fraser and Mitchell ${ }^{5}$ noted "precipitated senility" in Down's syndrome, changes in cognition and behaviour with increasing age have been documented. ${ }^{6-12}$ Many of these changes correspond to manifestations found in primary degenerative dementia of the Alzheimer type. A $30 \%$ incidence rate of dementia in Down's syndrome subjects older than 35 years has recently been reported. ${ }^{13}$

A pathological basis for the regression of mental status has been suggested. Brains of Down's syndrome subjects older than 35 years show decreased brain weight, gyral atrophy (cerebral), enlarged ventricles, senile plaques, neurofibrillary tangles, granulovacuolar neuronal degeneration, ${ }^{13-16}$ and reduced concentrations of choline acetyltransferase. ${ }^{17}$ This 
neuropathology occurs in the same regions in brains of Down's syndrome subjects as in brains of patients with Alzheimer's disease. ${ }^{1516}$

As a reflection of neuronal activity, brain oxidative metabolism has been studied in adults with Down's syndrome. Investigations using the Kety-Schmidt nitrous oxide saturation technique failed to show a difference in the cerebral metabolic rate for oxygen (CMRO2) in Down's syndrome as compared with age-matched controls. ${ }^{18} 19$ In the latter study ${ }^{19}$ halothane anaesthesia was used in the subjects. An investigation with $133 \mathrm{Xe}$ inhalation also failed to show differences in cerebral blood flow (CBF). ${ }^{20}$ Although not specifically looked for, age-related differences in CMRO2 and CBF in Down's syndrome were not demonstrated and dementia was not examined.

In an initial report from this laboratory, the cerebral metabolic rate for glucose (CMRglc) as measured with positron emission tomography (PET) was noted to be significantly greater in young Down's syndrome individuals than in healthy young controls. ${ }^{21}$ However, a uniform elliptical attenuation correction was employed with the ECAT II scanner. The present study extends this early report, in order to determine if there are age-related differences in CMRglc in Down's syndrome, and to examine the relation between CMRglc and cognitive function on the one hand and dementia on the other. An abstract of part of this work has been published. ${ }^{22}$

\section{Materials and methods}

\section{Selection of subjects}

The Down's syndrome group consisted of 14 young adults aged 19-33 years (10 men and four women, mean 25.9 years), four older non-demented adults (three males 49, 50 , 50 years; female 55 years), and two older demented adults (males 47, 63 years). All Down's syndrome subjects, recruited from family or group homes, had trisomy 21 karyotype. With the exception of two younger Down's syndrome subjects and one older nondemented subject, none had lived in an institution.

Screening included a review of the medical history, a thorough physical examination and the following laboratory studies: routine blood counts and serum chemistry, thyroid function tests, VDRL, ANA, serum folate and B12, ECG, and chest radiographs.

Several young adult Down's syndrome subjects had potentially confounding medical problems: subclinical hypothyroidism [2 (one euthyroid on medications)]; cardiac disease [four systolic murmurs (two normal EKG/ECHO; one normal EKG, no ECHO; one normal EKG, ECHO compatible with aortic insufficiency); two rightward axis and no murmur (one ECHO compatible with aortic insufficiency)]; enlarged cerebral ventricles on CT scan. (1) Of the older Down's syndrome group. two nondemented subjects were subclinically hypothyroid, one nondemented subject was euthyroid on thyroid replacement, and two demented subjects had gait difficulties and systolic murmurs (one right axis deviation and probable right ventricular hypertrophy on EKG and normal ECHO; one first degree AV block, ECHO unsatisfactory due to poor window). The latter subject also had rigidity, tremor, and a $S$. aureus bacteruria.

With these exceptions, the Down's syndrome subjects had no other disease, particularly no additional neurologic, psychiatric, or systemic medical disorder. None was taking medications (except for thyroid medications as noted above), or had a history of alcohol or drug abuse.

The male controls included 15 young volunteers aged 20-35 years (mean age $27 \cdot 1$ years) and 20 older volunteers aged 45-64 years (mean age 56.1 years). For a description see Duara et al. ${ }^{23} 24$

\section{Consent}

Screened control subjects were asked to sign an informed consent describing the purpose of the study, the tests performed, and the risks involved, including radiation

\section{Table 1 Criteria used to diagnose dcmentia in Down's} syndrome

A A loss of intellectual abilities of sufficient severity to interfere with social or occupational functioning.

1. Loss of skills for daily living:
(a) personal hygiene: brushing teeth, combing hair, washing face, bathing, shaving;
(b) eating;
(c) toileting: urine, bowel;
(d) dressing;
(e) managing a home: cleaning, shopping, cooking.

2. Loss of vocational skills.

B Memory impairment.

C At least one of the following:

1. Impairment of abstract thinking.

2. Impaired judgement: disregard of curfew, playing with fire, disregard of traffic.

3. Other disturbances of higher cortical function:
(a) aphasia: loss of vocabulary, difficulty with comprehension, echolalia, halting speech;
(b) apraxia;
(c) agnosia;
(d) visuospatial difficulty.

4. Personality change:

(a) loss of usual affectionate response to others;

(b) hyperkinetic, impulsive: low frustration level, temper tantrums, irritable, spiteful, obstinate, destructive, demanding, aggressive;

(c) withdrawal: slowness, loss of interest in surroundings, apathy, sudden changes from cheerfulness to sullenness, inattentiveness to vocational tasks, loss of social interests:

(d) automatic movements: rocking, wiggling hands, perseveration, stereotypies (speech, motor);

(e) psychiatric changes: hallucinations (auditory, visual), paranoid delusions, depression.

Supportive evidence for dementia:

Neurological signs:

1. Seizures.

2. Gait difficulties: shuffling, incoordination.

3. Release signs: grasp (palmar, plantar), snout, suck, palmomental, glabells.

4. Babinski.

5. Gegenhalten: increased tone.

6. Tremor; myoclonus. 
exposure. Total radiation exposure was maintained below limits established for normal volunteers in medical research. For the Down's syndrome subjects, family and/or legal guardian were required to sign the informed consent. The research was conducted under NIH protocol 81-AG-10A.

Dementia in Down's syndrome: criteria

Dementia in Down's syndrome was diagnosed using modified criteria from the Diagnostic and Statistical Manual of Mental Disorders ${ }^{25}$ (table 1). For each Down's syndrome subject, a caretaker (family or staff) was interviewed and was asked to fill out a questionnaire about daily living skills. If the subject was working, we contacted the employer. Available medical records and neuropsychological test scores were reviewed. Information also was obtained from neuropsychiatric interviews and neuropsychological tests (see below).

\section{Neuropsychology}

A neuropsychological assessment of Down's syndrome subjects was performed using three standardised tests. Because there was dysarthria in many cases the Peabody Picture Vocabulary Test-Revised ${ }^{26}$ was used to assess general intelligence. In this test of vocabulary, the subject points to pictures that depict meanings of words. This test measures a wide range of ability. Visuospatial ability was assessed with the Block Pattern Subtest of the Hiskey Nebraska Test of Learning Aptitude, ${ }^{27}$ the WISC-R Block Design Subtest, ${ }^{28}$ and the Extended Block Design Test (a simplified block design test for low ability subjects, Haxby $\mathbf{J}$, unpublished). Attention was assessed using forward digit span, object pointing span, and block tapping span. Visual recognition memory was measured with a design span (a test of immediate visual recognition memory for nonrepresentational geometric objects).

\section{PET technique}

After a 4-6 hour fast, indwelling arterial and venous catheters were inserted. One hour later the subject was blindfolded and ears plugged, and was placed on a bed in a darkened room. Following a 30 minute accommodation period, the subject was given 3-5 millicuries of [18F]2-fluoro-2-deoxy-D-glucose (18FDG) intravenously. $18 F D G$ was prepared by the method of Shiue et al. ${ }^{29}$ [18F]F2 was produced at the Naval Research Laboratory 76 " cyclotron via the $20 \mathrm{Ne}(\alpha, \alpha) 18 \mathrm{~F}$ nuclear reaction. The isotonic, buffered product was checked for chemical and radio-chemical purity using both high pressure liquid chromatography and thin layer chromatography.

Blood samples were obtained at timed intervals from injection until the end of scanning and were centrifuged to provide plasma for measurements of radioactivity and of glucose (Glucose Analyzer II, Beckman Instruments Co, Oxnard, CA). Forty five minutes after the 18FDG was injected, the blindfold and ear plugs were removed and up to seven serial PET slices were obtained parallel to and from 5 to $100 \mathrm{~mm}$ above the inferior orbito-meatal (IOM) line. PET scans were performed with an ECAT II positron tomograph (ORTEC, Life Sciences, Oak Ridge, TN) in the mediumresolution mode (full width at half maximum, $1.7 \mathrm{~cm}$ in image and axial planes). ${ }^{23}$ PET slices had at least 750,000 coincidence counts and were $1.4 \mathrm{~cm}$ apart.
PET images were reconstructed and corrected for attenuation with the ORTEC-supplied attenuation correction programme, using a uniform attenuation coefficient ( $\mu=0.088)$ and an operator drawn ellipse to define the edge of the skull. Owing to brachycephaly, microcephaly, and reduced skul thickness in Down's syndrome, absolute values of CMRglc will be presented in both Down's syndrome and control groups, but differences in absolute values between the two populations will not be analysed in this paper, but will be discussed elsewhere (Bacharach S, Schapiro MB, in preparation). After comparing PET images with anatomical sections from an atlas of a human brain, ${ }^{30} \mathrm{a}$ "height above the IOM line" of the slice in the atlas was assigned to the PET slices. Anatomical regions of interest (ROIs) in the PET scans then were identified. ${ }^{23}$ For the present study absolute values of hemispheric (CMRglc) and regional (rCMRglc) cerebral metabolic rate for glucose are presented. Lateral cortical regions were grouped as follows: frontal association, perirolandic sensorimotor, parietal association, occipital lobe and lateral temporal lobe. Mean ECAT numbers and mean areas of each ROI in a given slice were determined as described by Duara et al. ${ }^{23}$ ECAT numbers were converted to brain radioactivities (in microcuries per gram) with a calibration factor derived by prior scanning of a water filled flask that contained a known uniform concentration of 18FDG.

From brain radioactivity, time of scanning, plasma radioactivity, and plasma glucose level, rCMRglc was calculated in units of $\mathrm{mg} / 100 \mathrm{gm} / \mathrm{min}$ using a four-transfer-constant operational equation, with a "lumped constant" equal to $0 \cdot 418$. $^{31} \mathrm{~A}$ weighted mean rCMRglc was calculated, as some regions appeared in one or more adjacent slices. The following equation was used, where $i=1,2 \ldots$ equals slice number, rCMRglc equals the cerebral metabolic rate for glucose in the region within slice $\mathrm{i}$, and $\mathrm{Ni}$ is the area (in pixels) of the region within slice $i$,

$$
\text { weighted rCMRglc }=\frac{\sum_{i}(\mathrm{rCMRglc}) \mathrm{i} \mathrm{Ni}}{\sum_{i} \mathrm{Ni}}
$$

For the entire hemisphere, rCMRglc in the preceding equation equalled the weighted mean hemispheric metabolic rate for glucose (CMRglc), where $\mathrm{i}=1,2 \ldots 5$ equal individual slices between 30 and $80 \mathrm{~mm}$ above the IOM line and $\mathrm{Ni}$ is the surface area of the hemisphere within the slice i. CMRglc was calculated with grey matter transfer constants. ${ }^{23}$

\section{Other measurements}

Prior to the injection of $18 \mathrm{FDG}$, supine resting heart rate and systolic and diastolic blood pressures were measured. These values were compared with determinations obtained after at least 5 minutes of rest in the supine position on a non PET day.

An anxiety rating was assigned to each subject after PET scanning. The rating was based on the subject's verbal comments of distress, facial expression, motor activity (fidgeting), and evidence of excessive sweating or hyperventilation prior to and during the PET scan. These observations were ranked on an anxiety scale of 0 (minimal anxiety) to 3 (intense anxiety). ${ }^{24}$ 
Table 2 Physiologic data on Down's syndrome (DS) subjects and controls from PET and non PET days, expressed as mean \pm standard error

\begin{tabular}{|c|c|c|c|c|}
\hline \multirow[b]{2}{*}{ Variable } & \multicolumn{2}{|l|}{ Down's syndrome } & \multicolumn{2}{|l|}{ Controls } \\
\hline & Young & Old & Young & Old \\
\hline $\begin{array}{l}\text { Age (yr) } \\
\text { Height (cm) }\end{array}$ & $\begin{array}{r}25.9 \pm 1.2(14)^{*} \\
155.0 \pm 1.8(14) \dagger\end{array}$ & $\begin{array}{c}52 \cdot 3 \pm 2 \cdot 4(6) \\
152 \cdot 2 \pm 2 \cdot 3(6) \ddagger\end{array}$ & $\begin{array}{r}27 \cdot 1 \pm 1.2(15) \\
179.5 \pm 1.8(15)\end{array}$ & $\begin{array}{r}56.1 \pm 1.4(20) \\
177.3 \pm 1.6(20)\end{array}$ \\
\hline $\begin{array}{l}\text { Measurements on non-PET day } \\
\text { Heart rate (beats/min) } \\
\text { Systolic blood pressure }(\mathrm{mm} \mathrm{Hg}) \\
\text { Diastolic blood pressure }(\mathrm{mm} \mathrm{Hg})\end{array}$ & $\begin{aligned} 68 \cdot 0 & \pm 2 \cdot 1(14) \\
108 \cdot 0 \pm & 3 \cdot 5(14) \dagger \\
69 \cdot 7 & \pm 2 \cdot 4(14) \dagger\end{aligned}$ & $\begin{array}{r}68 \cdot 3 \pm 3 \cdot 8(6) \\
102 \cdot 3 \pm 3 \cdot 3(6) \pm \\
68 \cdot 7 \pm 3 \cdot 8(6)_{+}^{\ddagger}\end{array}$ & $\begin{array}{r}69 \cdot 1 \pm 2 \cdot 3(15) \\
122 \cdot 6 \pm 2 \cdot 7(15) \\
78 \cdot 0 \pm 2 \cdot 3(15)\end{array}$ & $\begin{array}{r}68 \cdot 6 \pm 3 \cdot 3(18) \\
127 \cdot 1 \pm 3 \cdot 0(18) \\
82 \cdot 8 \pm 1 \cdot 7(18)\end{array}$ \\
\hline $\begin{array}{l}\text { Measurements on PET day } \\
\text { Heart rate (beats/min) } \\
\text { Systolic blood pressure }(\mathrm{mm} \mathrm{Hg}) \\
\text { Diastolic blood pressure }(\mathrm{mm} \mathrm{Hg}) \\
\text { Anxiety rating }(0-3) \\
\text { Mean glucose }(\mathrm{mg} / 100 \mathrm{ml})\end{array}$ & $\begin{aligned} & 75.1 \pm 3.6(13) \\
& 111.9 \pm 2.2(13) \dagger \\
& 71.7 \pm 1.8(13) \\
& 1.8 \pm 0.4(11) \\
& 85.9 \pm 2.3(12)\end{aligned}$ & $\begin{aligned} 67 \cdot 0 \pm 4 \cdot 3(6) \\
102 \cdot 7 \pm 2 \cdot 3(6) \pm \\
66 \cdot 2 \pm 3 \cdot 2(6) \pm \\
0 \cdot 3 \pm 0 \cdot 3(6) \\
87 \cdot 0 \pm 2 \cdot 6(6)\end{aligned}$ & $\begin{array}{r}66.7 \pm 2.8(15) \\
121.0 \pm 2.0(15) \\
75.9 \pm 1.7(15) \\
1.5 \pm 0.2(14) \\
84.5 \pm 1.7(15)\end{array}$ & $\begin{array}{r}67 \cdot 2 \pm 2 \cdot 7(19) \\
124 \cdot 7 \pm 4 \cdot 0(19) \\
78 \cdot 8 \pm 2 \cdot 3(19) \\
1 \cdot 1 \pm 0 \cdot 2(19) \\
87 \cdot 1 \pm 1 \cdot 5(20)\end{array}$ \\
\hline
\end{tabular}

*Mean \pm S.E.M. Number of subjects in parentheses.

+ Differs from mean in young controls by Bonferroni $T$ statistic $(p<0.05)$

$\ddagger$ Differs from mean in old controls by Bonferroni T statistic $(p<0.05)$.

Differences between means in young and old control and DS groups were analysed with a one-way ANOVA. Post hoc comparisons, using Bonferroni t tests $(\mathrm{p}<0.05)$, were as follows: young DS vs young controls, old DS vs old controls, young DS vs old DS, and young controls vs old controls. No significant differences in heart rate, and systolic and diastolic blood pressures on PET and non PET days were found in young or old DS groups.

\section{Statistics}

Differences between mean values for CMRglc in the young and old control and Down's syndrome groups were analysed with a one-way ANOVA, ${ }^{32}$ and Bonferroni $t$ statistics. $^{32}$ Homogeneity of variance was examined with Bartlett's test. ${ }^{32}$ The criterion of statistical significance was $p<0.05$. A Wilcoxon 2 Sample Test was used to compare young and old Down's syndrome subjects for neuropsychologic data. ${ }^{33}$

\section{Results}

Table 2 summarises physiological data on the Down's syndrome subjects, including measurements from PET and non PET days. Because brains of Down's syndrome subjects older than 35 years show neuropathological ${ }^{13-16}$ and neurochemical ${ }^{17}$ changes of Alzheimer's disease, the Down's syndrome group first was divided into individuals younger and older than 35 years. The mean ages of the young and old Down's syndrome and control groups were similar. Down's syndrome subjects, both young and old, were significantly shorter than their age matched control groups. Supine resting heart rate and systolic and diastolic blood pressures were not significantly different on PET and non PET days for both young and old Down's syndrome subjects. Further, the anxiety rating, another measure of stress, did not differ between any of the groups (young Down's syndrome vs young controls, old Down's syndrome vs old controls, or young Down's syndrome vs old Down's syndrome). For the physiological parameters on the day of PET, the young Down's syndrome group differed from the young control group only in having a lower supine systolic blood pressure; the older Down's syndrome group had significantly lower supine systolic and diastolic blood pressures than did the old control group. Comparison of the young and old Down's syndrome subjects on days of PET showed no significant differences.

In the older Down's syndrome group, the diagnosis of dementia was established in two subjects aged 47

Table 3 Neuropsychology test scores for young and old DS groups expressed as mean \pm standard deviation

\begin{tabular}{|c|c|c|}
\hline & Young DS & Old DS \\
\hline $\begin{array}{l}\text { Language } \\
\text { Peabody Picture Vocabulary } \\
\text { Test Age (yr) }\end{array}$ & $5 \cdot 7 \pm 2 \cdot 3(14)$ & $2.6 \pm 0.6(6)^{*}$ \\
\hline $\begin{array}{l}\text { Visuospatial } \\
\text { Hiskey Nebraska Block Pattern } \\
\text { Subtest (score) } \\
\text { WISC-R Block Design Subtest } \\
\text { (score) } \\
\text { Extended Block Design Test } \\
\text { (score) }\end{array}$ & $\begin{array}{r}3 \cdot 1 \pm 1 \cdot 5(14) \\
7 \cdot 2 \pm 8 \cdot 5(14) \\
13 \cdot 4 \pm 2 \cdot 4(14)\end{array}$ & $\begin{array}{l}0.5 \pm 0.8(6)^{*} \\
1.5 \pm 3.7(6)^{*} \\
7.3 \pm 4.8(6)^{*}\end{array}$ \\
\hline $\begin{array}{l}\text { Attention } \\
\text { Digit Span (score) } \\
\text { Object Pointing Span (score) } \\
\text { Block Tapping Span (score) }\end{array}$ & $\begin{array}{l}10.9 \pm 4.7(14) \\
11.0 \pm 2.9(11) \\
14.4 \pm 6.0(14)\end{array}$ & $\begin{array}{l}7.3 \pm 6.0(6) \\
7.2 \pm 4.9(6)^{*} \\
7.7 \pm 5.0(6)^{*}\end{array}$ \\
\hline $\begin{array}{l}\text { Visual Recognition Memory } \\
\text { Design Span (score) }\end{array}$ & $4.9 \pm 2.5(14)$ & $1.8 \pm 1.7(6)^{*}$ \\
\hline
\end{tabular}

*Differences between mean values in young and old DS groups were compared with a Wilcoxon 2 Sample Test $(p<0.05)$.

Values are mean \pm SD.

Number of subjects is shown in parentheses. 
and 63 years with a 2 year history of mental decline. As illustrated in table 3, the mean mental age of the young Down's syndrome group, as determined by the Peabody Picture Vocabulary Test, ${ }^{26}$ was $5 \cdot 7 \pm 2 \cdot 3$ (SD) years. Two young Down's syndrome subjects had mental ages of 9.4 years and 11.75 years, whereas the remaining 12 had mental ages ranging from 3.4 to 6.5 years.

Table 3 also shows that there was a clear difference in standardised neuropsychologic tests of language, visuospatial ability, attention, and visual recognition memory between the young and older Down's syndrome groups. On the Peabody Picture Vocabulary Test, the mean mental age was 2.6 years in the old Down's syndrome group as compared with 5.7 years in the young Down's syndrome group. Individually, the scores of three of four nondemented Down's syndrome subjects were more similar to the score of the demented old group. One nondemented older subject had scores on several tests within the lower range of the younger Down's syndrome group.

Table 4 lists values for the weighted hemispheric cerebral metabolic rate for glucose and for rCMRglc in five pairs of bilaterally symmetrical lobar brain regions. Hemispheric CMRglc equalled 6.57 $\mathrm{mg} / 100 \mathrm{gm} / \mathrm{min}$ in the 14 young Down's syndrome subjects, as compared with $5.02 \mathrm{mg} / 100 \mathrm{gm} / \mathrm{min}$ in the young controls. There was a uniform elevation in rCMRglc in 14 young adult Down's syndrome subjects in comparison with young controls. However, as an operator-drawn ellipse was employed to calculate absolute values of rCMRglc, and might have led to abnormally high values of rCMRglc in this study, further work is required with transmission attenuation to determine what the difference between young Down's syndrome and control groups actually represents (Bacharach S, Schapiro $\mathbf{M}$, in preparation). No difference in mean asymmetry between young Down's syndrome and control groups was present for lobar rCMRglc. No differences in cerebral metabolism existed between the young and older control groups. ${ }^{23} 24$

As shown in table 4, a comparison was also made between young and older Down's syndrome groups with respect to weighted hemispheric CMRglc and rCMRglc. Hemispheric CMRglc in the older Down's syndrome group was $23 \%$ less than in the young Down's syndrome group $(p<0.05)$. Hemispheric CMRglc equalled $5.12 \mathrm{mg} / 100 \mathrm{gm} / \mathrm{min}$ in the six older Down's syndrome subjects. Significant decreases were present in all lobar regions (table 5). No differences existed in mean asymmetry between young and old Down's syndrome groups.

Table 5 illustrates quotients of rCMRglc in association regions to rCMRglc in sensorimotor and occipital areas, which were examined in order to reduce the large coefficient of variation associated with $\mathrm{CMRglc}^{24}$ for statistical analysis, and because these quotients have been noted to be reduced in Alzheimer's disease. ${ }^{34}$ No differences were present between the young Down's syndrome and young control groups, but the parietal/sensorimotor and temporal/occipital quotients were reduced

Table 4 Hemispheric and lobar cerebral metabolic rates for glucose in DS and control groups expressed as mean \pm standard error

\begin{tabular}{|c|c|c|c|c|}
\hline \multirow[b]{2}{*}{ Brain region } & \multicolumn{2}{|l|}{ Controls } & \multicolumn{2}{|l|}{ Down's syndrome } \\
\hline & Young & Old & Young & Old \\
\hline \multicolumn{5}{|l|}{ Hemisphere } \\
\hline $\begin{array}{l}\text { Right } \\
\text { Left }\end{array}$ & $\begin{array}{l}5.02 \pm 0.17(15)^{*} \\
5.12 \pm 0.17(15)\end{array}$ & $\begin{array}{l}4.65 \pm 0.25(20) \\
4.73 \pm 0.25(20)\end{array}$ & $\begin{array}{l}6 \cdot 57 \pm 0 \cdot 20(14) \\
6 \cdot 60 \pm 0.22(14)\end{array}$ & $\begin{array}{l}5.10 \pm 0.46(6) \dagger \\
5.14 \pm 0.43(6) \dagger\end{array}$ \\
\hline \multicolumn{5}{|l|}{ Frontal } \\
\hline $\begin{array}{l}\text { Right } \\
\text { Left }\end{array}$ & $\begin{array}{l}5.92 \pm 0 \cdot 26(15) \\
6.02 \pm 0.27(15)\end{array}$ & $\begin{array}{l}5.33 \pm 0.28(20) \\
5.38 \pm 0.28(20)\end{array}$ & $\begin{array}{l}7.81 \pm 0.25(14) \\
7.90 \pm 0.25(14)\end{array}$ & $\begin{array}{l}6.17 \pm 0.47(6) \dagger \\
6.05 \pm 0.47(6) \dagger\end{array}$ \\
\hline $\begin{array}{c}\text { Parietal } \\
\text { Right } \\
\text { Left }\end{array}$ & $\begin{array}{l}5.83 \pm 0.26(15) \\
5.86 \pm 0.25(15)\end{array}$ & $\begin{array}{l}5.32 \pm 0.26(20) \\
5.46 \pm 0.28(20)\end{array}$ & $\begin{array}{l}7.42 \pm 0.26(14) \\
7.53 \pm 0.28(14)\end{array}$ & $\begin{array}{l}5.42 \pm 0.63(6) \dagger \\
5.44 \pm 0.61(6) \dagger\end{array}$ \\
\hline \multicolumn{5}{|l|}{ Sensorimotor } \\
\hline $\begin{array}{l}\text { Right } \\
\text { Left } \\
\text { Occipital }\end{array}$ & $\begin{array}{l}6 \cdot 17 \pm 0 \cdot 29(15) \\
6 \cdot 13 \pm 0 \cdot 25(15)\end{array}$ & $\begin{array}{l}5.61 \pm 0.29(19) \\
5.82 \pm 0.31(19)\end{array}$ & $\begin{array}{l}7.85 \pm 0.27(14) \\
8.03 \pm 0.27(14)\end{array}$ & $\begin{array}{l}6.22 \pm 0.60(6) \dagger \\
6.39 \pm 0.56(6) \dagger\end{array}$ \\
\hline $\begin{array}{l}\text { Right } \\
\text { Left }\end{array}$ & $\begin{array}{l}5 \cdot 49 \pm 0 \cdot 16(15) \\
5.55 \pm 0 \cdot 17(15)\end{array}$ & $\begin{array}{l}5.36 \pm 0.26(20) \\
5.41 \pm 0.25(20)\end{array}$ & $\begin{array}{l}6.57 \pm 0.23(14) \\
6.59 \pm 0.22(14)\end{array}$ & $\begin{array}{l}5.65 \pm 0.44(6) \dagger \\
5.72 \pm 0.43(6) \dagger\end{array}$ \\
\hline $\begin{array}{l}\text { Temporal } \\
\text { Right } \\
\text { Left }\end{array}$ & $\begin{array}{l}4 \cdot 71 \pm 0 \cdot 19(15) \\
4.93 \pm 0 \cdot 20(15)\end{array}$ & $\begin{array}{l}4.50 \pm 0.21(20) \\
4.56 \pm 0.19(20)\end{array}$ & $\begin{array}{l}5.81 \pm 0.22(14) \\
5.89 \pm 0.18(14)\end{array}$ & $\begin{array}{l}4.48 \pm 0.40(6) \dagger \\
4.30 \pm 0.33(6) \dagger\end{array}$ \\
\hline
\end{tabular}

*Mean \pm SEM; number of subjects in parentheses.

+ Differs from mean in young Down's syndrome by Bonferroni t statistic $(p<0.05)$

Values are rCMRglc $\mathrm{mg} / 100 \mathrm{gm} / \mathrm{min}$. Differences between means in young and old DS and control groups were analysed with a one-way ANOVA. Post hoc comparisons, using Bonferronit tests $(p<0.05)$, were as follows: young DS vs old DS, and young controls vs old controls. Homogeneity of variance was assured by using Bartlett's test. 
Table 5 Ratios of lobar metabolic rates for glucose, parietal/sensorimotor and temporal/occipital

\begin{tabular}{|c|c|c|c|c|}
\hline & \multicolumn{2}{|l|}{ Controls } & \multicolumn{2}{|l|}{ Down's syndrome } \\
\hline & Young & rCM Rgic ratios & Young & Old \\
\hline \multicolumn{5}{|c|}{ Parietal/Sensorimotor +} \\
\hline $\begin{array}{l}\text { Right } \\
\text { Leftll }\end{array}$ & $\begin{array}{l}0.949 \pm 0.012(15)^{*} \\
0.957 \pm 0.012(15)\end{array}$ & $\begin{array}{l}0.950 \pm 0.012(19) \\
0.942 \pm 0.011(19)\end{array}$ & $\begin{array}{l}0.946 \pm 0.010(14) \\
0.937 \pm 0.012(14)\end{array}$ & $\begin{array}{l}0.863 \pm 0.031(6) \dagger \\
0.848 \pm 0.045(6)\end{array}$ \\
\hline \multicolumn{5}{|l|}{ Temporal/Occipital§ } \\
\hline $\begin{array}{l}\text { Right } \\
\text { Left }\end{array}$ & $\begin{array}{l}0.859 \pm 0.028(15) \\
0.890 \pm 0.031(15)\end{array}$ & $\begin{array}{l}0.845 \pm 0.018(20) \\
0.849 \pm 0.018(20)\end{array}$ & $\begin{array}{l}0.887 \pm 0.022(14) \\
0.898 \pm 0.017(14)\end{array}$ & $\begin{array}{l}0.797 \pm 0.043(6) \\
0.757 \pm 0.036(6) \dagger\end{array}$ \\
\hline
\end{tabular}

*Mean \pm SEM. Number of subjects in parentheses.

†Differs from mean in young Down's syndrome by Bonferroni $t$ statistic $(p<0.05)$.

+Parietal/Sensorimotor.

\$Temporal/Occipital.

Inhomogeneous variance (Bartlett's test)

Differences between mean values in young and old DS and control groups were analysed with a one-way ANOVA. Post hoc comparisons, using Bonferroni t tests $(p<0.05)$, were as follows: young DS vs old DS, and young controls vs old controls. Homogeneity of variance was assured by using Bartlett's test.

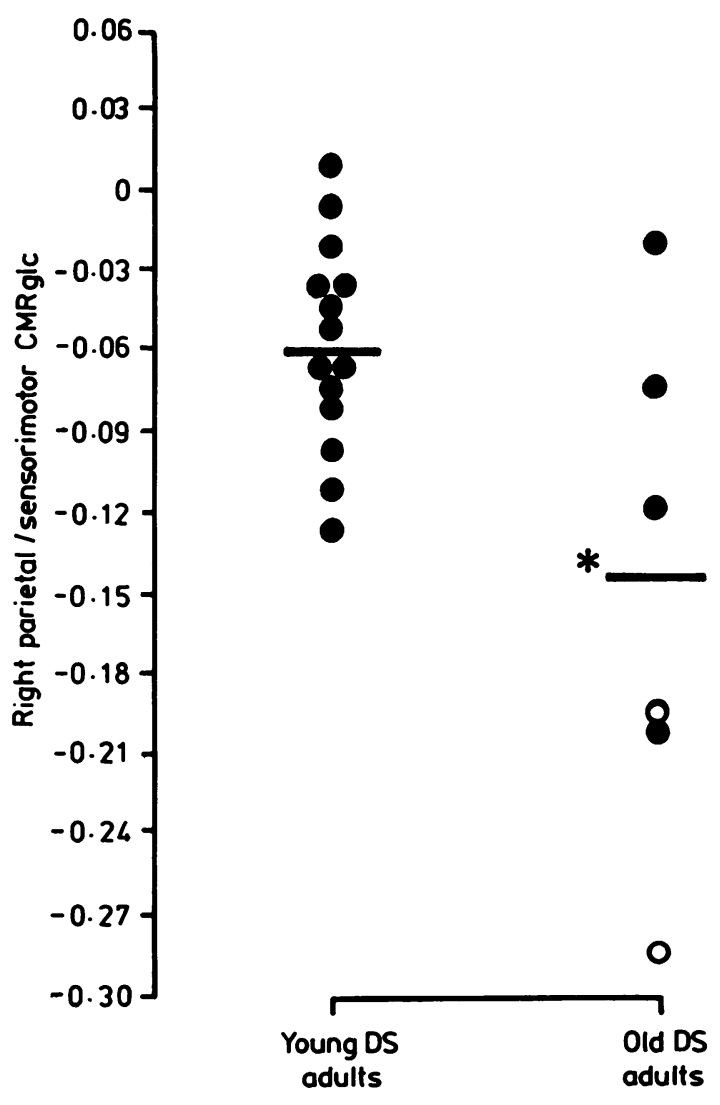

Fig Scatter plot of the ratio of right parietal/sensorimotor rCMRglc in young and old Down's syndrome groups. Means are indicated by lines. An asterisk indicates that the mean of the old Down's syndrome group was significantly less than the mean in the young Down's syndrome group (Student's t test, $p<0.05)$. Open circles indicate demented older Down's syndrome subjects, closed circles indicate nondemented Down's syndrome subjects. significantly in the old Down's syndrome as compared with the young Down's syndrome group. Because of nonhomogeneous variances, the differences were significant only for right parietal/sensorimotor and left temporal/occipital ratios. The figure illustrates that three older Down's syndrome subjects fell outside the range of values of the young Down's syndrome group. The subjects with the lowest and third lowest values were demented. The subject with the second lowest value (female aged 55 yr) developed dementia within one year of her PET scan.

\section{Discussion}

This study shows that older adult Down's syndrome subjects with trisomy 21 have a reduced cerebral metabolic rate for glucose measured at rest and with reduced sensory input as compared with young subjects. Mean hemispheric metabolism in the older Down's syndrome subjects was $23 \%$ less than in the younger Down's syndrome group, and rCMRglc was reduced in all lobar regions of the older subjects. Differences between groups for mean right/left ratios for rCMRglc were not present.

In agreement with others, ${ }^{35}$ we noted variability of mental age scores in young adult Down's syndrome subjects, with most subjects being moderately to severely retarded, as measured by the Peabody Picture Vocabulary Test. Our study also revealed significant differences between young and older adult Down's syndrome subjects in neuropsychological parameters studied, as has been noted previously. ${ }^{6-12}$ Neuropsychological test scores in the nondemented old Down's syndrome subjects were more similar to those of the demented old Down's syndrome group than to the younger Down's syndrome group. Thus, all older subjects showed neuro- 
psychologic reductions compared with young subjects. These differences may be associated with the neuropathology of Alzheimer's disease. Dementia, when it appears, may reflect higher threshold amount of brain damage in brains of Down's syndrome subjects over 35 years of age. In this regard, the brain of a 47 year old demented subject who died demonstrated very high numbers of senile plaques, neurofibrillary tangles, and neuronal loss. ${ }^{36}$

Although all Down's syndrome brains appear to show neuropathology of Alzheimer's disease after age 35 years, only 20 to $30 \%$ of older Down's syndrome subjects have been described as demented during life. ${ }^{8111437}$ Some authors believe that the density of senile plaques and neurofibrillary tangles correlates with the severity of dementia $;{ }^{13}$ others disagree. ${ }^{14}$ As all of our older Down's syndrome subjects showed neuropsychological performance below that of younger Down's syndrome subjects, this discrepancy again suggests that dementia requires more brain disease to appear than does cognitive decline (see above). Alternatively, the discrepancy may be due in part to difficulties in diagnosing dementia in mentally retarded subjects ${ }^{3839}$ and to the variable age of onset and clinical course of dementia in Down's syndrome.

A limitation to the interpretation of our study arises from its cross-sectional design. The quality of health care available to our younger Down's syndrome subjects is better than that afforded the older subjects when they were younger, and the younger subjects had better educational opportunities. To minimise this effect, our Down's syndrome subjects were recruited from homes, rather than from institutions, as we hoped that stimulation and learning would be better in a home situation.

Symmetry of cerebral metabolism has not been examined previously in adult Down's syndrome. The bilateral symmetry of rCMRglc in young adult Down's syndrome in this study is in agreement with the lack of focal neuropathology seen in young adult Down's syndrome brains ${ }^{14}$ and is similar to the symmetry seen in the controls.

An increased cerebral metabolic rate for glucose was noted in young adult Down's syndrome subjects as compared with controls, but the extent to which the increase reflects errors in attenuation correction due to the smaller head size in Down's syndrome with the ECAT II tomograph currently is under investigation (Bacharach $\mathbf{S}$, Schapiro $\mathbf{M}$, in preparation). Increased glucose utilisation also has been reported in adult autism, another functional disturbance of brain function without evident neuropathology and with normal head size. ${ }^{40}$

Age-related changes in brain metabolism, measured at rest and with reduced sensory input were not seen when healthy young and old controls were com- pared in our study, in support of previous findings from this laboratory. ${ }^{2324}$ However, for the old Down's syndrome subjects, mean CMRglc was significantly less than for the young Down's syndrome subjects. Such a decrease has not been reported previously, and contrasts with the lack of an age effect in healthy controls. It is likely that they correspond to Alzheimer type neuropathology and cognitive decline in the older Down's syndrome subjects.

Anxiety has been reported to increase brain metabolism, ${ }^{4142}$ but in our study, heart rate, blood pressure, and assessment of global anxiety during PET did not differ between young and old Down's syndrome subjects. In addition, heart rate and blood pressure did not differ on PET and non PET days, suggesting that the young Down's syndrome subjects were not markedly anxious during PET. Unregulated sensory deprivation also might decrease brain metabolism, ${ }^{43}$ but both our Down's syndrome subjects and controls were treated equally with respect to sensory inputs and were adapted to the procedure. Although partial voluming may average the radioactive measurements in subjects with enlarged ventricles or sulci, quantitative CT analysis suggests that CSF volume increases with age in Down's syndrome, but that the increase is not different from that in controls. (Schapiro M, unpublished observations).

Decreased glucose utilisation has been described in Alzheimer's disease. ${ }^{3444-46}$ In agreement with these? studies, we found that the parietal and temporal lobess were relatively more affected in Down's syndrome than were perirolandic sensorimotor and occipitas regions. The age decrement in brain metabolism in Down's syndrome also coincides with the appearance of Alzheimer type neuropathology. There is a reduction in cholinergic and noradrenergic activity, ${ }^{1747}$ as well as neuronal loss, senile plaques, neurofibrillary tangles, and granulovacuolar degener-

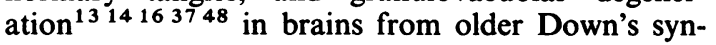
drome subjects. The density of senile plaques and of neurofibrillary tangles and the degree of cell loss in the hippocampus and temporal cortex are comparable to those reported in Alzheimer's brains. ${ }^{163648}$ Furthermore, the density of senile plaques and neurofibrillary tangles increases with age in Down's syndrome. ${ }^{131437}$

The authors thank Alice Cheng for her assistance with the computer programs.

\section{References}

1 Zellweger H. Down syndrome. In: Vinken PJ, Bruyn GW, eds. Handbook of Clinical Neurology, vol 31. New York: North Holland Publishing Company, 1977: 
367-469.

2 Benda CE. Down's Syndrome. New York: Grune and Stratton, 1969:139-65.

3 Wisniewski KE, French JH, Rosen JF, et al. Basal ganglia calcification (BGC) in Down's syndrome (DS): another manifestation of premature aging. Ann $N Y$ Acad Sci 1982;396:179-89.

4 Ross MH, Galaburda AM, Kemper TL. Down's syndrome: is there a decreased population of neurons? Neurology 1984;34:909-16.

5 Fraser MB, Mitchell A. Kalmuc idiocy: report of a case with autopsy with notes on sixty-two cases. J Ment Sci 1876;22:169-79.

6 Owens D, Dawson JC, Losin S. Alzheimer's disease in Down's syndrome. Am J Ment Def 1971;75:606-12.

7 Dalton AJ, Crapper DR, Schlotterer GR. Alzheimer's disease in Down's syndrome: visual retention deficits. Cortex 1974;10:366-77.

8 Dalton AJ, Crapper DR. Down's syndrome and aging of the brain. In: Mittler P, ed. Research to Practice in Mental Retardation. Baltimore: University Park Press, 1977:391-400.

9 Wisniewski K, Howe J, Williams DG, Wisniewski HM. Precocious aging and dementia in patients with Down's syndrome. Biol Psychiatry 1978;13:619-27.

10 Liss L, Shim C, Thase M, et al. Relationship between Down syndrome (DS) and dementia Alzheimer type (DAT). J Neuropathol Exp Neurol 1980;39:371.

11 Thase ME, Liss L, Smeltzer D, Maloon J. Clinical evaluation of dementia in Down's syndrome: a preliminary report. J Ment Defic Res 1982;26:239-44.

12 Thase ME, Tigner R, Smeltzer DJ, Liss L. Age-related neuropsychological deficits in Down's syndrome. Biol Psychiatry 1984;19:571-85.

13 Wisniewski KE, Wisniewski HM, Wen GY. Occurrence of neuropathological changes and dementia of Alzheimer's disease in Down syndrome. Ann Neurol 1985;17:278-82.

14 Ropper AH, Williams RS. Relationship between plaques, tangles, and dementia in Down syndrome. Neurology 1980;30:639-44.

15 Ball MJ, Nuttall K. Topography of neurofibrillary tangles and granulovacuoles in hippocampi of patients with Down's syndrome: quantitative comparison with normal ageing and Alzheimer's disease. Neuropathol Appl Neurobiol 1981;7:13-20.

16 Mann DMA, Yates PO, Marcyniuk B. Alzheimer's presenile dementia, senile dementia of Alzheimer type and Down's syndrome in middle age form an age related continuum of pathological changes. Neuropathol Appl Neurobiol 1984;10:185-207.

17 Yates CM, Simpson J, Maloney AFJ, Gordon A, Reid AH. Alzheimer-like cholinergic deficiency in Down syndrome. Lancet 1980;ii:979.

18 Fazekas JF, Ehrmantraut WR, Shea JG, Kleh J. Cerebral hemodynamics and metabolism in mental deficiency. Neurology 1958;8:558-60.

19 Lassen NA, Christensen S, Hoedt-Rasmussen K, Stewart BM. Cerebral oxygen consumption in Down's syndrome. Arch Neurol 1966;15:595-602.

20 Risberg J. Regional cerebral blood flow measurements by $133 \mathrm{Xe}$ inhalation: methodology and applications in neuropsychology and psychiatry. Brain Lang 1980; 9:9-34.

21 Schwartz M, Duara R, Haxby J, et al. Down's syndrome in adults: brain metabolism. Science 1983;221:781-3.

22 Schapiro MB, Duara R, Grady CL, et al. Brain metabolism in demented and nondemented Down's syndrome. Neurology 1984;34(suppl 1):122.

23 Duara R, Margolin RA, Robertson-Tchabo EA, et al. Cerebral glucose utilization as measured with positron emission tomography in 21 resting healthy men between the ages of 21 and 83 years. Brain 1983;106:761-75.

24 Duara R, Grady C, Haxby J, et al. Human brain glucose utilization and cognitive function in relation to age. Ann Neurol 1984;16:702-13.

25 American Psychiatric Association Task Force on Nomenclature and Statistics: Diagnostic and Statistical Manual for Mental Disorders, 3rd ed. Washington, DC: American Psychiatric Association, 1980.

26 Dunn LM, Dunn LM. Peabody Picture Vocabulary Test-Revised. Circle Pines, New Mexico: American Guidance Service, 1981.

27 Hiskey MS. Hiskey-Nebraska Test of Learning Aptitude. Lincoln, Nebraska: College View Printers, 1955.

28 Wechsler D. Wechsler Intelligence Scale for ChildrenRevised. New York: Psychological Corporation, 1974.

29 Shiue CY, Salvadori PA, Wolf AP, Fowler JS, MacGregor R. A new improved synthesis of 2-deoxy-2-[18F]fluoro-d-glucose from 18F-labeled acetyl hypofluorite. J Nucl Med 1982;23:899-903.

30 Eycleshymer AC, Schoemaker DM. A Cross-Section Anatomy. New York: Appleton, 1911.

31 Huang SC, Phelps ME, Hoffman EJ, et al. Noninvasive determination of local cerebral metabolic rate of glucose in man. Am J Physiol 1980;238:E69-E82.

32 Miller RG Jr. Simultaneous Statistical Inference. New York: McGraw-Hill, 1966:67-70.

33 Snedecor GW, Cochran WG. Statistical Methods. Ames Iowa: The Iowa State University Press, 1980:144.

34 Haxby J, Duara R, Grady C, Cutler N, Rapoport S. Relations between neuropsychological and cerebral metabolic asymmetries in early Alzheimer's disease. $J$ Cereb Blood Flow Metabol 1985;5:193-200.

35 Gath A. Cerebral degeneration in Down's syndrome. Dev Med Child Neurol 1981;23:814-7.

36 Ball MJ, Schapiro MB, Rapoport SI. Neuropathological relationships between Down syndrome and senile dementia Alzheimer type. In: Epstein C, ed. The Neurobiology of Down Syndrome. New York: Raven Press, 1986:45-58.

37 Wisniewski KE, Wisniewski HM. Age-associated changes and dementia in Down's syndrome. In: Reisberg B, ed. Alzheimer's Disease. New York: The Free Press, 1983:319-26.

38 Reiss S, Leviton GW, Szyszko J. Emotional disturbance and mental retardation: diagnostic overshadowing. Am J Ment Def 1982;86:567-74.

39 Miniszek NA. Development of Alzheimer disease in Down syndrome individuals. Am J Ment Def 1983; 87:377-85.

40 Duara R, Rumsey J, Grady C, et al. Cerebral glucose metabolism in adult autism. Neurology 1984;34(suppl 
1): 117.

41 Kety SS. Circulation and metabolism of the human brain in health and disease. Am J Med 1950;8:205-17.

42 Reivich M, Alavi A. Effect of psychophysiological stimuli on local cerebral glucose consumption in humans. In: Greitz T, Ingvar DH, Widen L, eds. The Metabolism of the Human Brain Studied with Positron Emission Tomography. New York: Raven Press, 1985: 305-13.

43 Mazziotta JC, Phelps ME, Carson RE, Kuhl DE. Tomographic mapping of human cerebral metabolism: sensory deprivation. Ann Neurol 1982;12:435-44.

44 De Leon MJ, Ferris SH, George AE, et al. Computed tomography and positron emission transaxial tomography evaluations of normal aging and Alzheimer's

\author{
disease. J Cereb Blood Flow 1983;3:391-4.
}

45 Friedland RP, Budinger TF, Ganz E, et al. Regional cerebral metabolic alterations in dementia of the Alzheimer type: positron emission tomography with [18F]fluorodeoxyglucose. J Comput Assist Tomogr 1983;7:590-8.

46 Foster NL, Chase TN, Mansi L. Cortical abnormalities in Alzheimer's disease. Ann Neurol 1984;16:649-54.

47 Yates CM, Ritchie IM, Simpson J, Maloney AFJ, Gordon A. Noradrenaline in Alzheimer-type dementia and Down syndrome. Lancet 1981;ii:39-40.

48 Ball MJ, Nuttall K. Neurofibrillary tangles, granulovacuolar degeneration, and neuron loss in Down syndrome: quantitative comparison with Alzheimer's dementia. Ann Neurol 1980;7:462-5. 